\title{
ANALISIS PERMUKAAN ZEOLIT ALAM MALANG YANG MENGALAMI MODIFIKASI PORI DENGAN UJI SEM-EDS
}

\author{
Anton Prasetyo ${ }^{1}$, Rini Nafsiati ${ }^{2}$, Susi Nurul Kholifah ${ }^{1}$, Agie Botianovi ${ }^{1}$ \\ ${ }^{1}$ Kelompok Riset Kimia Fisika Material, Jurusan Kimia, UIN Maulana Malik Ibrahim Malang \\ ${ }^{2}$ Fakultas Tarbiyah, UIN Maulana Malik Ibrahim Malang
}

\begin{abstract}
Nature zeolit is pore material much benefitted in industry sector as adsorben, katalis and many other else. The existence of this material in Indonesia is very exuberate, one of them is Malang. The efforts to improve zeolit quality have already much done by many researchers. In this research, there has been done characterization and zeolit modification in Malang land become mesopori material by using surfaktan CTAB as template. To characterize pore can be done by SEM test and to know the element content can be done by EDS test. From this, we know that from SEM test got result that mophologi structure of zeolit grain generally contains lempengs arranged insmoothly and tend to be amorf shape. SEM test is incapable to identify pore of zeolit such as preparasi, kalsinasi or modified zeolit in order unidentified took pore changing. The result of EDS test occur that the changing of element content of nature zeolit composer in dealuminasi process. So there is changing of ratio Si/Al in nature zeolit where it is 3.002 and after dealuminasi 1.8994. Whereas the element content after modification is similar with element content in zeolit having dealuminasi.
\end{abstract}

Keywords: Nature zeolit, Surfaktan, Morphology surface, SEM-EDS.

\section{A. PENDAHULUAN}

Zeolit alam sangat berlimpah keberadaannya di wilayah Indonesia di anataranya ada didaerah Bayah Banten, Tasikmalaya, Lampung, dan Malang Selatan. Daerah Malang Selatan. Merupakan daerah penghasil zeolit dengan kandungan mineral zeolit sebanyak 4,8 juta ton (Trisunaryanti, 2005).

Kandungan utama zeolit alam Indonesia adalah mineral modernit sekitar 60-70\%, sisanya dalah klinoptilolit Kristal dan kwarsa amorpus (Trisunaryanti, dkk., 1996). Zeolit alam jenis modernit merupakan material mikropori yang memiliki ukuran pori kisaran di bawah $20 \AA$, sehingga kemampuan penyerapan dan difusi reaktan pada katalis sangat terbatas untuk molekul yang berukuran besar (Sutarti \&
Rachmawati, 1994). Salah satu cara untuk meningkatkan daya guna zeolit alam yaitu dengan memodifikasi pori zeolit alam dengan cara melebarkan ukuran pori menjadi mesopori (Taguchi dkk, 2004). Inovasi ini akan meningkatkan nilai ekonomis dan nilai guna zeolit alam lokal serta nantinya dapat diterapkan dibidang industri petroleum dan biodiesel yang reaksinya melibatkan molekul berukuran besar.

Setiadi dan Astri, (2007) melaporkan hasil karakterisasi zeolit alam Malang dengan kandungan modernit yang relatif tinggi dan tercampur dengan jenis klinoptilolit serta beberapa senyawa pengotor. Zeolit jenis modernit banyak diaplikasikan di industri kimia, karena memiliki stabilitas termal yang tinggi dan mampu mempertahankan strukturnya 
sampai temperatur $800-900{ }^{\circ} \mathrm{C}$ dan juga stablilitas yang cukup tinggi terhadap asam. Dan untuk meningkatkan pemanfaatan zeolit alam malang, maka dalam penelitian ini akan dilakukan modifikasi zeolit alam malang menjadi material mesopori. Dalam penelitian ini akan dimodifikasi pori zeolit alam malang dengan penambahan template surfaktan CTAB yang berfungsi untuk mempersar ukuran pori sehingga didapat material zeolit mesopori.

Scanning Electron Microscopy (SEM) adalah mikroskop electron yang dapat digunakan untuk mempelajari detil arsitektur permukaan material dalam daerah makro dan submikron. SEM merupakan teknik analisis menggunakan elektron sebagai sumber pencitraan dan medan elektromagnetik sebagai lensanya. Perbesaran SEM yang dalam rentang perbesaran sekitar 100 kali - 300.000 kali diharapkan dapat mengidentifikasi perubahan pori yang terjadi pada zeolit sebelum dan sesudah modifikasi.. Dan SEM dilengkapi juga detector EDS, sehingga dapat menganalisis kandungan unsure yang terkandung dalam zeolit. (Anonymous, 20011. BPIB Jakarta, 2011, West, 1992).

\section{B. METODE PENELITIAN}

Batuan zeolit ditumbuk hingga halus dan diayak dengan ukuran lolos 200 mesh dan dicuci dengan akuades. Selanjutnya dikeringkan dalam oven pada suhu $120^{\circ} \mathrm{C}$ selama 4 jam. Dilanjutkan dengan proses dealuminasi zeolit alam dengan cara ; $200 \mathrm{~g}$ zeolit alam direndam dalam $400 \mathrm{~mL} \mathrm{HCl} 6 \mathrm{M}$ selama 4 jam, kemudian disaring dan dicuci dengan akuades hingga filtrat menunjukkan $\mathrm{pH}$ netral. Pencucian dihentikan apabila sudah tidak terdapat endapan pada filtrat ketika ditambah dengan $\mathrm{Ag}^{+}$.Setelah kering, zeolit kemudian direndam kembali dalam $400 \mathrm{~mL} \mathrm{NH} \mathrm{NO}_{3} 2 \mathrm{M}$ selama 4 jam. Campuran disaring dan dicuci dengan akuades hingga filtrat menunjukkan $\mathrm{pH}$ netral. Residu kemudian dikeringkan dalam oven $300^{\circ} \mathrm{C}$ selama 4 jam.

Zeolit hasil dealuminasi ditambahkan ke dalam larutan 1 $\mathrm{mol} / \mathrm{L} \quad$ tetrapropilamonium hidroksida (TPAOH), kemudian diaduk selama 15 menit, Campuran yang terbentuk dioven pada suhu $60^{\circ} \mathrm{C}$ selama 24 jam. Sejumlah setiltrimetil amonium bromida (CTABr) ditambahkan ke dalam campuran hingga diperoleh rasio molar $\mathrm{SiO}_{2} / \mathrm{CTAB}=3,85$, kemudian diaduk sampai tercampur sempurna. Selanjutnya dioven pada suhu $150{ }^{\circ} \mathrm{C}$ selama 48 jam. Padatan yang terbentuk, kemudian disaring, dicuci dengan aquadest dan dikeringkan pada suhu $60{ }^{\circ} \mathrm{C}$ selama 24 jam, selanjutnya pada suhu $110{ }^{\circ} \mathrm{C}$ selama 24 jam. Surfaktan $\left(\mathrm{CTA}^{+}\right)$dan templat organik $\left(\mathrm{TPA}^{+}\right)$dihilangkan dengan kalsinasi pada $550{ }^{\circ} \mathrm{C}$ selama 10 jam. Zeolit modifikasi yang terbentu selanjutnya dikarakterisasi dengan SEM-EDS.

\section{PEMBAHASAN}

\section{Karakterisasi SEM}

Untuk mengetahui morfologi permukaan zeolit uji maka dilakukan pengujian dengan menggunakan SEM (Scanning Electron Microscopy). Pengujian dilakukan pada sampek zeolit alam, zeolit hasil kalsinasi dan zeolit setelah dimodifikasi. Ini bertujuan untuk membandingkan, apakah terjadi 
perubahan pada sampel zeolit setelah dilakukan berbagai perlakuan.

Pada uji SEM pada zeolil alam yang asli didapatkan gambar sebagai berikut.

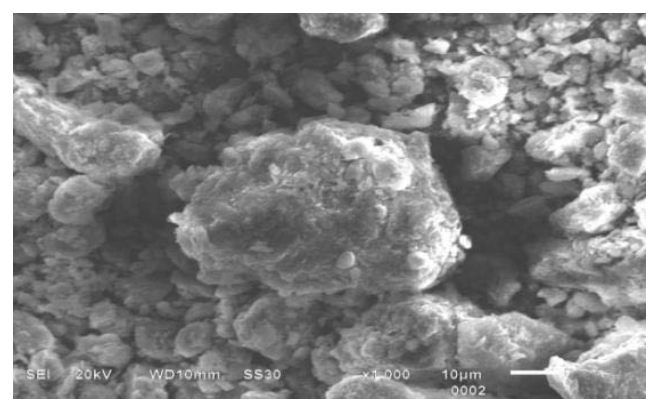

Gambar. 1 Foto SEM Zeolit Alam Pada Perbesaran $1000 \mathrm{x}$.

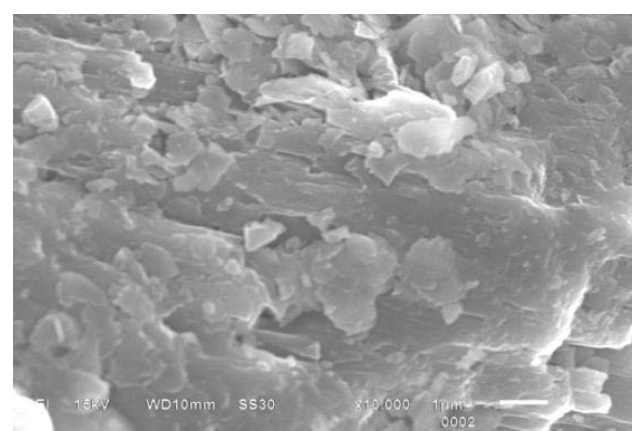

Gambar. 2. Foto SEM Zeolit Alam Pada Perbesaran $10.000 \mathrm{x}$.

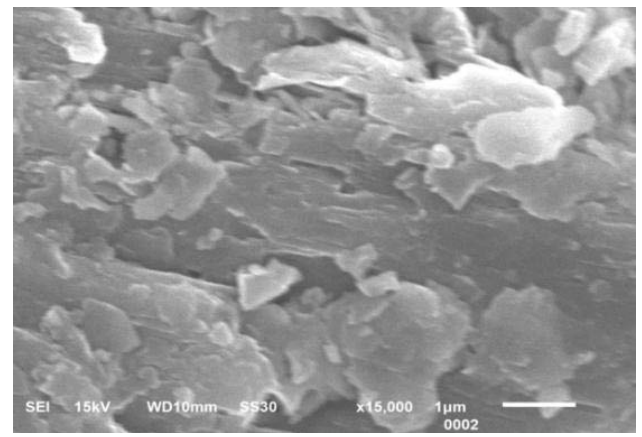

Gambar. 3. Foto SEM Zeolit Alam Pada Perbesaran $15.000 \mathrm{x}$.

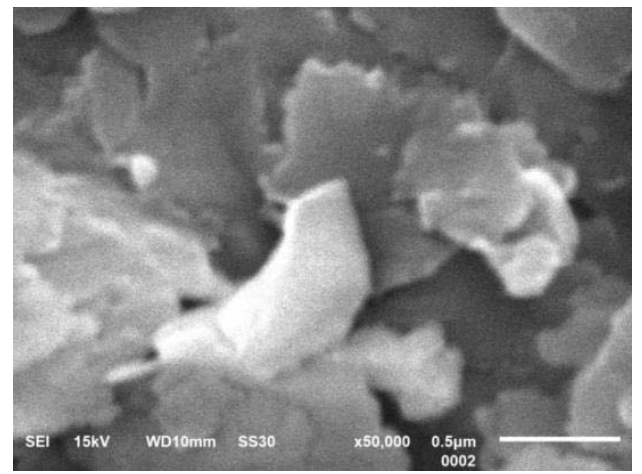

Gambar. 4. Foto SEM Zeolit Alam Pada Perbesaran $50.000 \mathrm{x}$.
Dari hasil pengukuran pada perbesaran 1000 kali, diketahui bahwa zeolit alam dari malang selatan terdiri dari butiran butiran dengan ukuran butiran yang tidak seragam. Hal ini dapat terjadi karena proses penghancuran zeolit alam yang tidak merata, sehingga distribusi ukuran butir menjadi berbeda. Dan analisis butiran dengan menggunakan pengukuran yang lebih besar ada pada gambar 2,3, dan 4 . Dan Diketahui bahwa zeolit alam terdiri dari lempeng lempeng yang tidak beraturan dan dengan ketebalan yang tipis. Untuk ukuran rongga atau pori juga tidak kelihatan, walaupun sudah diperbesar sampai perbesaran 50.000 kali.

Hasil uji SEM pada zeolit alam yang telah mengalami dealuminasi dan kalsinasi didapatkan seperti pada gambar dibawah ini.

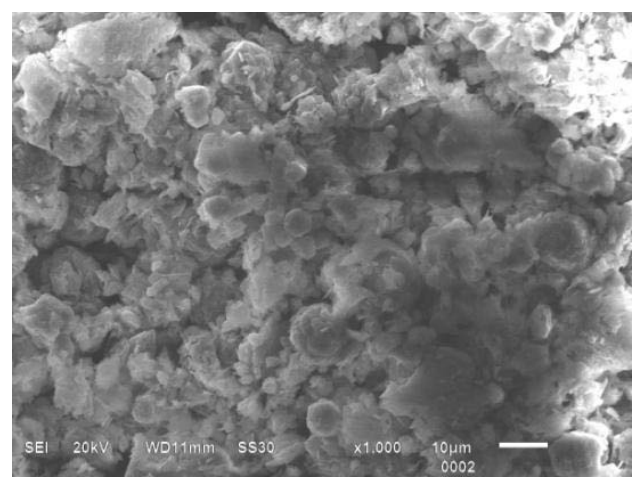

Gambar. 5 Foto SEM Zeolit Alam Setelah Kalsinasi Pada Perbesaran 1000 x.

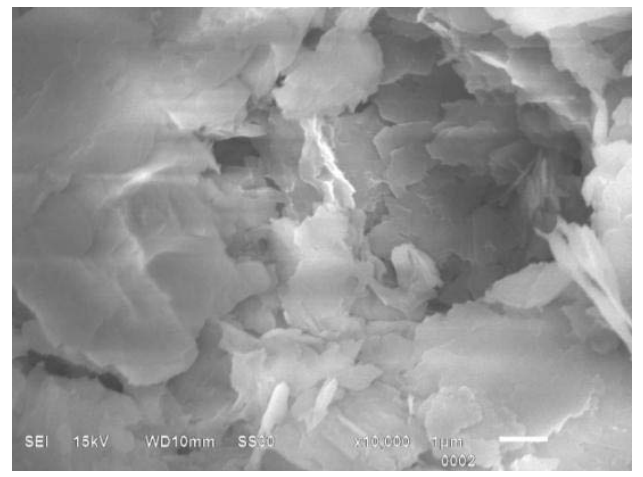

Gambar. 6 Foto SEM Zeolit Alam Setelah Kalsinasi Pada Perbesaran 10.000 x. 


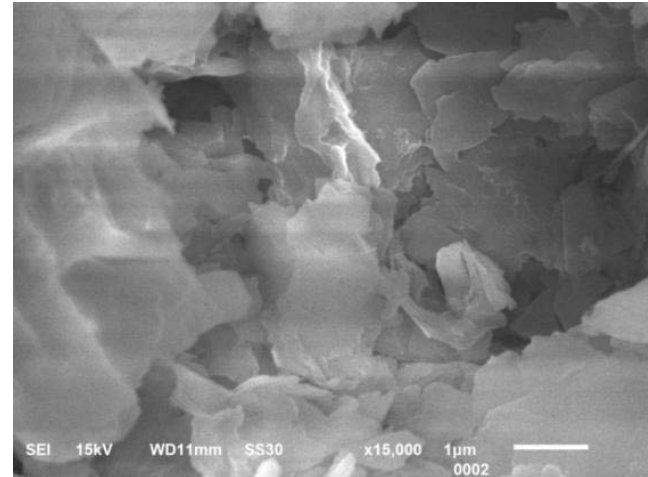

Gambar. 7 Foto SEM Zeolit Alam Setelah Kalsinasi Pada Perbesaran 15.000 x.

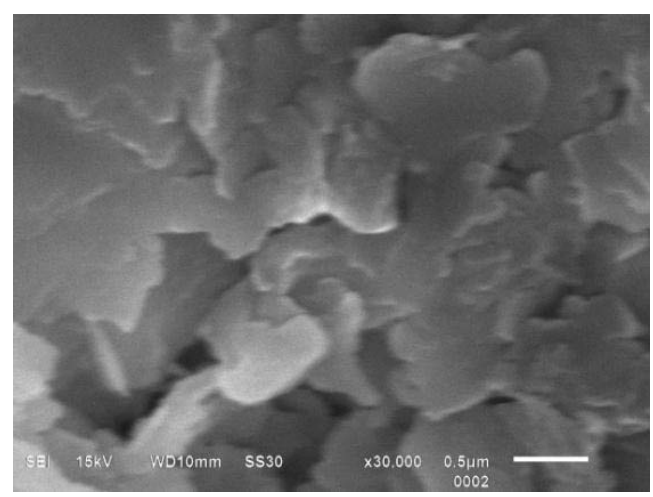

Gambar. 8 Foto SEM Zeolit Alam Setelah Kalsinasi Pada Perbesaran 30.000 x.

Pada gambar zeolit alam yang telah mengalami dealuminasi diketahui bahwa lempengan lempengan menjadi lebih kecil, dan terlihat memiliki struktur mekanik yang kuat. Hal ini disebabkan pada proses kalsinasi dan dealuminasi terjadi peristiwa keluarnya air dan juga oksida oksida logam sehingga yang semula mempunyai lempengan yang besar berubah menjadi lempengan lempengan yang kecil dan kuat.

Setelah proses kalsinasi, tahap berikutnya zeolit mengalami modifikasi, dan dari hasil foto SEM didapatkan hasil sebagai berikut :

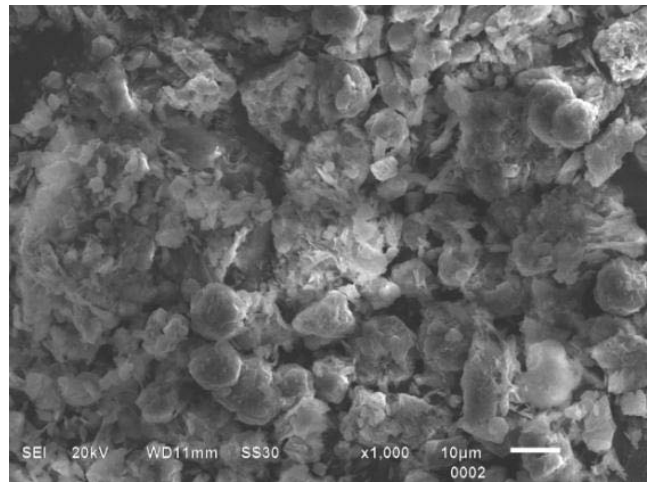

Gambar. 9 Foto SEM Zeolit Alam Setelah Modifikasi Pada Perbesaran 1000 x.

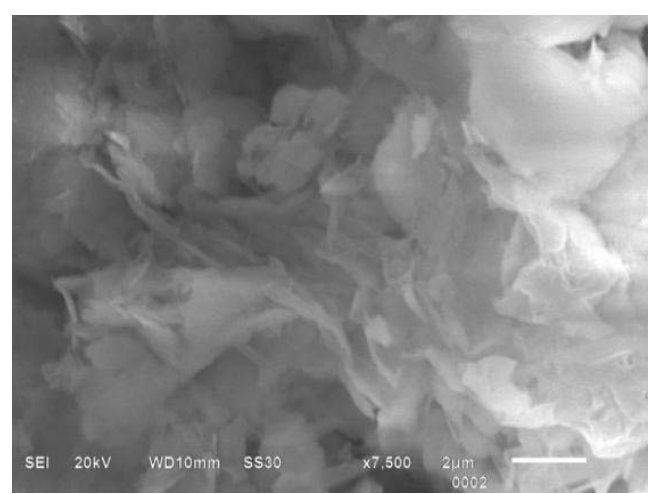

Gambar. 10. Foto SEM Zeolit Alam Setelah Modifikasi Pada Perbesaran 7500 x.

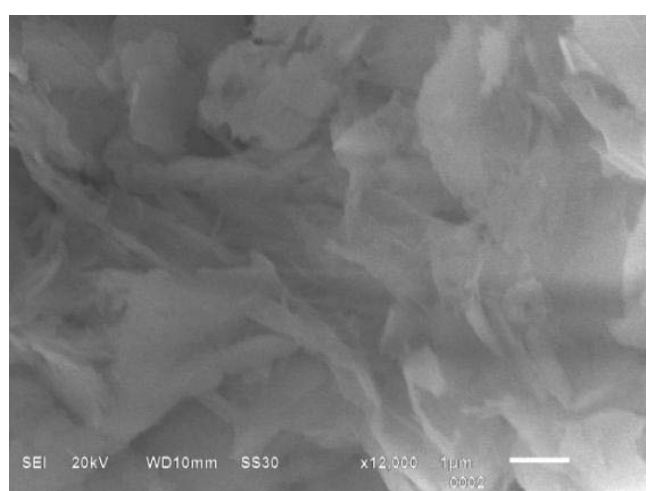

Gambar. 11. Foto SEM Zeolit Alam Setelah Modifikasi Pada Perbesaran 12.000 x.

Dari Uji SEM pada sampel yang sudah termodifikasi, maka dapat dilihat bahwa zeolit yang terbentuk juga terdiri dari lempengan lempengan kecil dan hampir sama pada foto zeolit yang telah mengalami proses kalsinasi dan dealuminasi. Dan dari SEM juga dapat diketahui bahwa belum dapat teridentifikasi adanya perubahan pori 
pada zeolit yang diuji. Hal ini bisa jadi karena keterbatasan magnifikasi pada alat SEM yang belum bisa mendeteksi pori zeolit yang ukurannya kecil. Oleh karenanya menjadi penting untuk dilakukan uji dengan adsorpsi gas nitrogen untuk mengetahui ukuran pori yang diperoleh.

\section{Karakterisasi EDS}

Karaketrisasi EDS dilakukan untuk mengetahui kandungan unsur unsur yang ada dalam zeolit. Hal ini karena ada beberapa bagian dari eksperimen yang bertujuan untuk proses dealuminasi terjadi peristiwa dekationasi yang disebabkan dengan penambahan $\mathrm{HCl}$, Dalam proses dealuminasi juga dilakukan pemanasan yang menyebabkan keluarnya air di rongga rongga zeolit dan juga logam logam lainnya. Mekanisme inilah yang menyebabkan kenaikan ratio $\mathrm{Si} / \mathrm{Al}$. Dengan meningkatnya rasio ini maka zeolit secara umum menjadi aktif. Sehingga dari dengan analisis EDS diharapkan dapat diketahui bahwa perubahan kandungan unsur unsur penyusun zeolit dalam tiap tahapan. Hasil analisis EDS dari tiap tahap
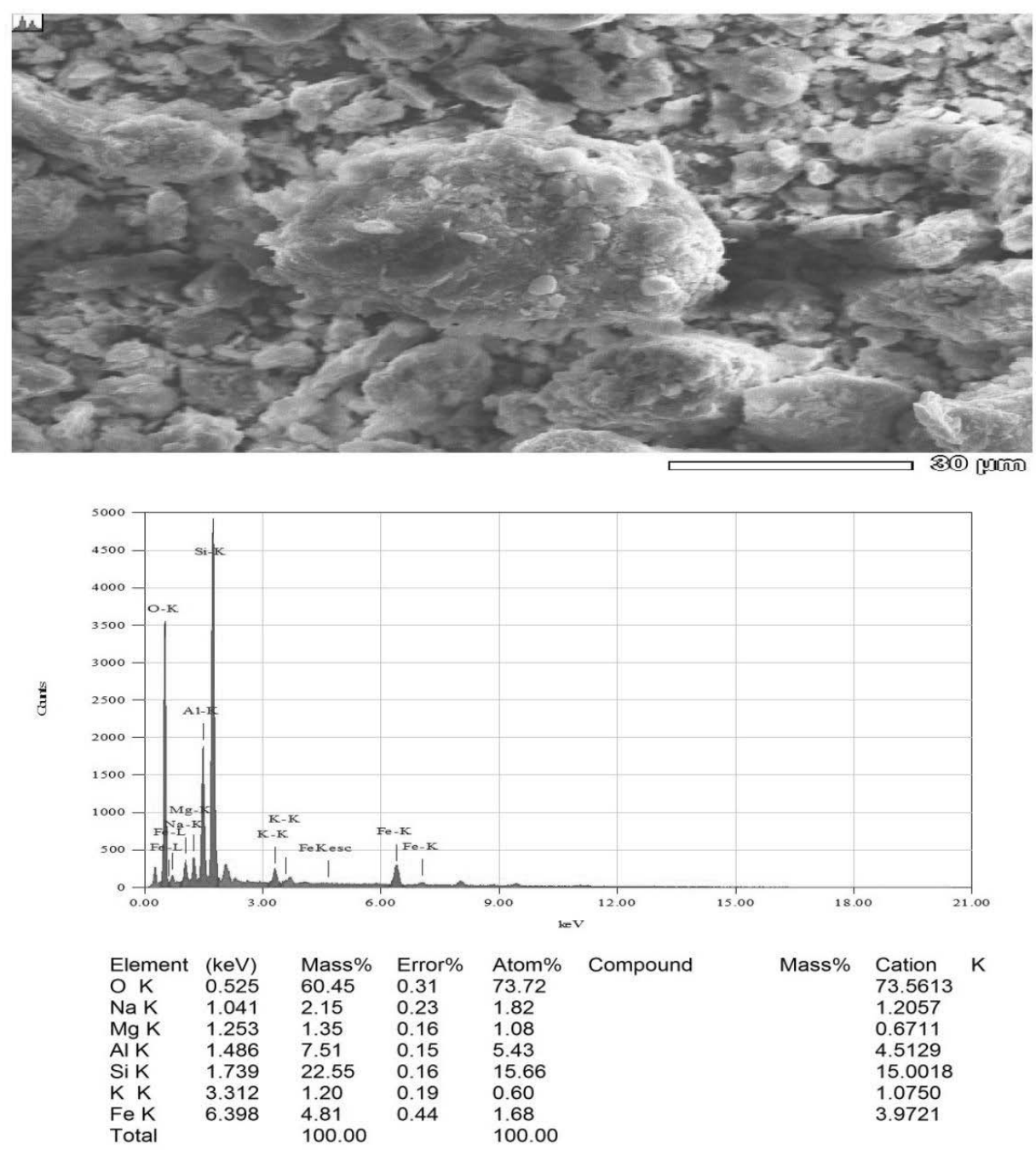

Gambar 12. Hasil Uji EDS Pada Zeolit Alam 
Dari hasil analisis EDS dapat diketahui bahwa sebagian besar senyawa penyusun zeolit alam malang selatan dalam bentuk oksida. Hal ini dapat diketahui dari hasil kandungan $\mathrm{O}$ yang cukup besar. Dan kemungkinan oksida yang terbesar adalah golongan Silika dan Alumina, karena kandungan Si dan Al adalah yang terbesar, dan ini sesuai dengan komposisi senyawa dari zeolit yang disusun atas senyawaan silica alumina. Dari hasil EDS juga dapat diketahui bahwa kadar Al adalah $7,51 \%$ dan $\mathrm{Si}$ adalah 22,55\%. Sehingga ratio $\mathrm{Si} / \mathrm{Al}$ nya adalah 3,002 .

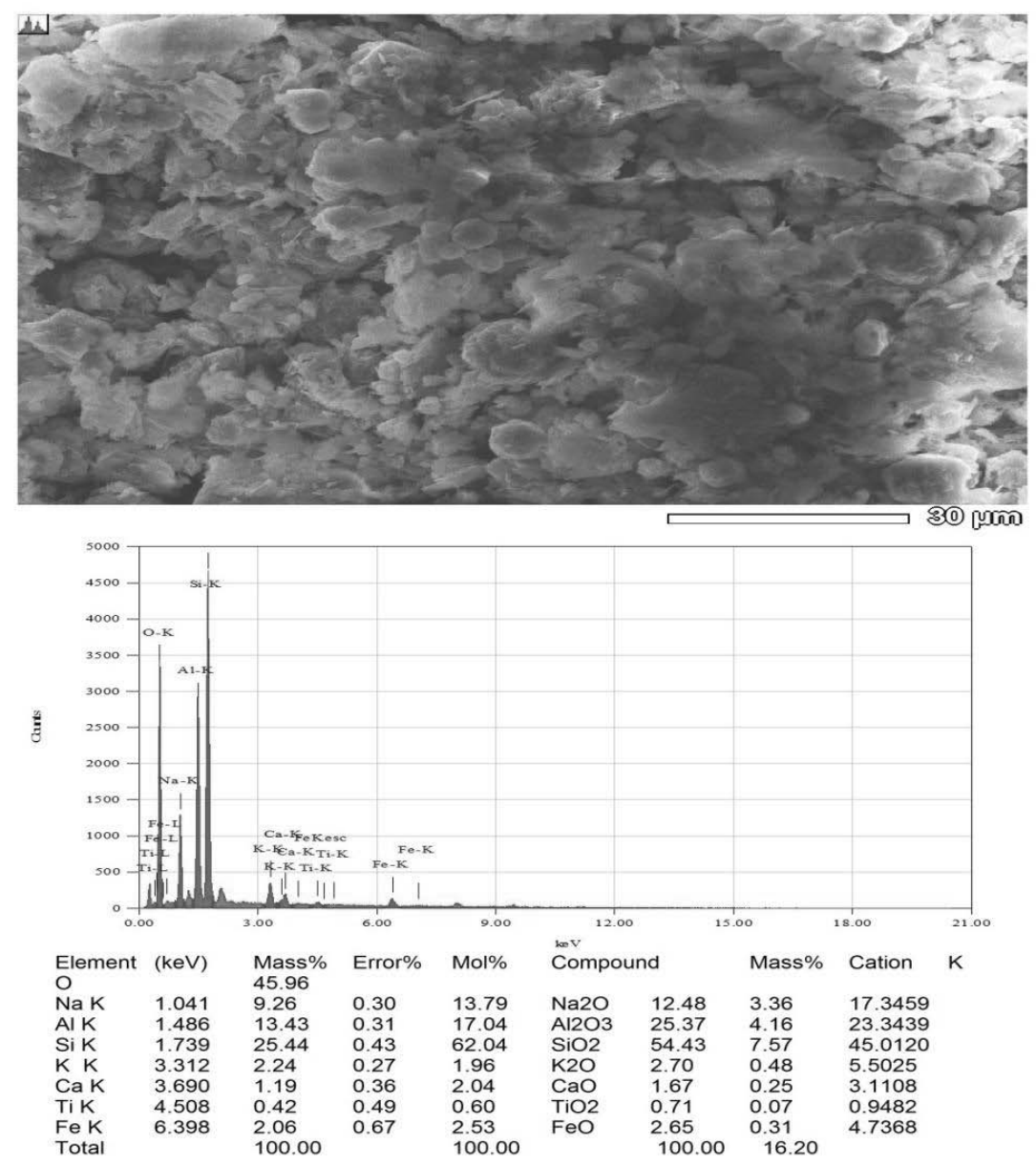

Gambar 13. Hasil Uji EDS Pada Zeolit Alam Yang Mengalami Dealuminasi

Dari hasil analisis EDS pada zeolit alam yang mengalami dealuminasi dapat diketahui bahwa ada beberapa perubahan kandungan unsur yaitu : Na, Al, Si. Dan muncul unsur baru yang tidak terdapat pada sebelum pengukuran yaitu $\mathrm{Ca}$. Sedangkan ratio $\mathrm{Si} / \mathrm{Al}$ juga berubah menjadi 1,894. Perubahan ini dikarenakan pada proses dealuminasi terjadi dekationasi dan juga pemanasan sehingga secara teoritis diharapkan terjadi pengurangan kation kation logam. Akan tetapi justru kation kation logam menjadi naik dan muncul kation logam $\mathrm{Ca}$. Ini dimungkinkan karena proses dealuminasi belum terdistribusi secara merata dan juga pengukuran EDS pada perbesaran 1000 kali sehingga wilayah deteksi menjadi lebih sempit dan wilayah yang 
dideteksi EDS merupakan wilayah yang kaya kation. Hasil yang berbeda dimungkinkan ada jika dilakukan pengukuran EDS pada area lain atau pada perbesaran yang lebih kecil.
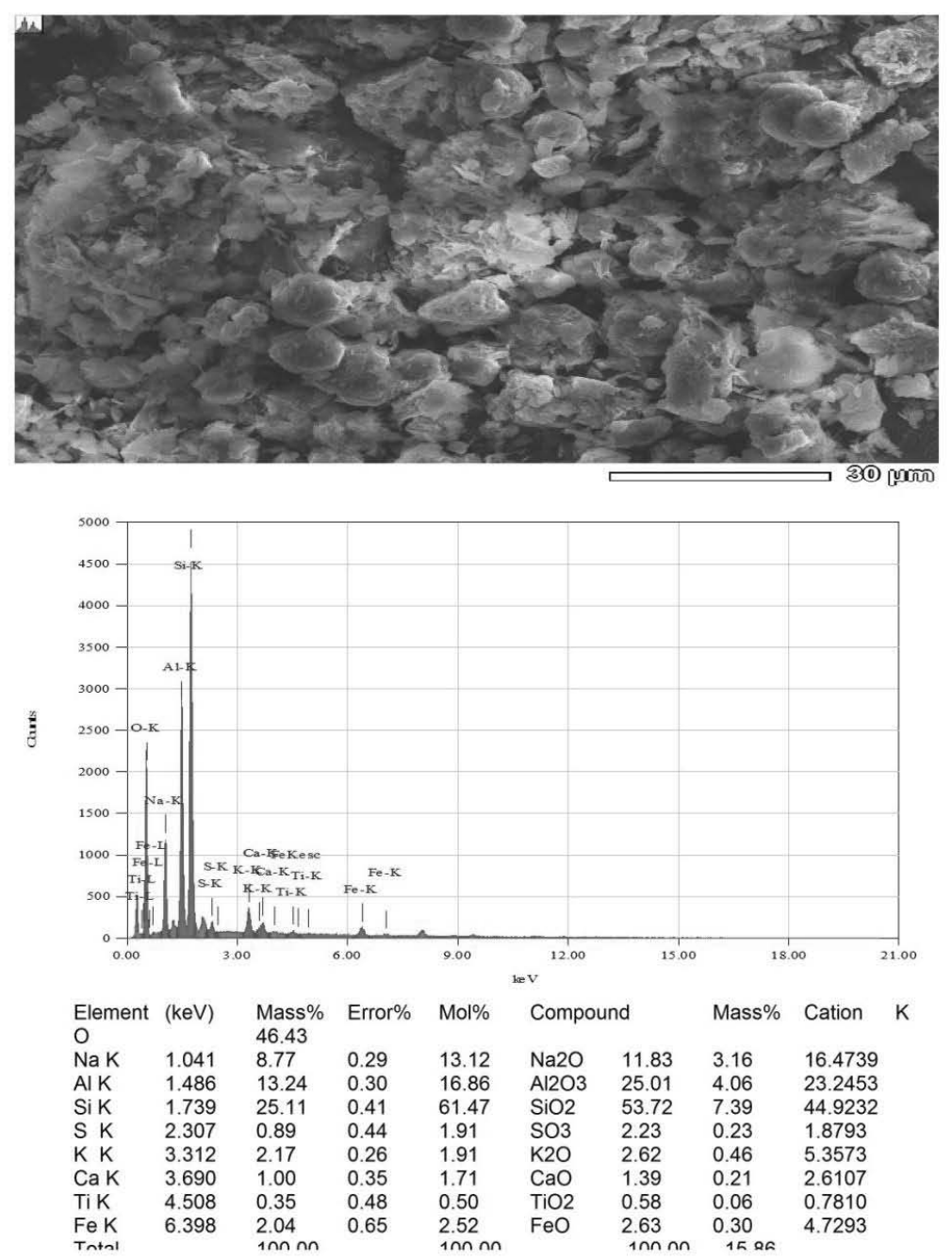

Gambar 14. Hasil Uji EDS Pada Zeolit Alam Termodifikasi

Dari hasil analisis EDS dapat diketahui bahwa setelah proses modifikasi, kandungan senyawa pada zeolit tidak mengalami perubahan di mana masih identik dengan senyawa zeolit yang mengalami dealuminasi dan terdiri dari senyawaan alumina silikat dan oksida oksida logam. Karena pada dasarnya, tujuan modifikasi adalah untuk memperbesar pori menjadi material mesopori dan tidak merubah kandungan unsur unsur penyusunnya..

\section{KESIMPULAN}

Dari uji SEM didapatkan hasil bahwa struktur morfologi zeolit secara umum terdiri dari lempeng lempeng yang tersusun tidak merata dan cenderung dalam bentuk amorf. Dari uji SEM belum mampu untuk mengidentifikasi dari pori dari zeolit baik yang belum dipreparasi, kalsinasi maupun zeolit termodifikasi. Dari uji EDS didapatkan hasil bahwa terjadi perubahan kandungan unsur penyusun zeolit alam pada proses 
dealuminasi. Sedangkan kandungan unsur setelah modifikasi relative sama dengan kandungan unsur pada zeolit yang mengalami dealuminasi.

\section{E. UCAPAN TERIMA KASIH}

Terima Kasih pada Lembaga Penelitian dan Pengembangan UIN Maulana Malik Ibrahim yang telah membiayai kegiatan penelitian ini melalui dana DIPA 2011.

\section{F. DAFTAR PUSTAKA}

Anonymous. 2011. Overview Microscope Optik v.s Scanning Electron Microscopy (SEM). http://file.upi.edu/Direktori/FPM IPA/JUR._PEND._KIMIA/19680 8031992031AGUS SETIABUDI/Bahan Kuli ah Karakterisasi Material/Bab 6 Teknik Mikroskopy SEM.pdf. diakses tanggal 3 Oktober 2011.

BPIB Jakarta. 2011. Scanning Electron Microscope (SEMEDAX).

http://bpibjakarta.com/index2.ph p? option $=$ com content $\& d o \quad p d f$ $=1 \& i d=36$. Diakses tanggal 3 Oktober 2011.

Setiadi dan Astri, 2007, Preparasi Dan Karakterisasi Zeolit Alam Untuk Konversi Senyawa ABE Menjadi Hidrokarbon, Prosiding Konggres Dan Simposium Nasional Kedua MKICS 2007 ISSN : $0216-4183$

Sutarti, M., dan Rachmawati, M., 1994, Zeolit Tinjauan Literatur, Pusat Dokumentasi dan Informasi Ilmiah LIPI: Jakarta.

Taguchi, Akira, Ferdi Schu"th. 2004. Ordered Mesopori Materials In Catalysis. Microporous and Mesoporous Materials. Volume 77, hal. 1-45.

Trisunaryanti, Wega. 2009. Modifikasi Zeolit Alam dan
Karakterisasinya untuk Katalis Proses Konversi Limbah Plastik dan Pelumas Menjadi Bahan Bakar. Material Canggih; Rekayasa Material Berbasis Sumber Daya Alam SilikaAlumina. Yogjakarta : Kelompok Minat Material Jurusan Kimia FMIPA Universitas Gadjah Mada.

West, A.R, 1992, Solid State Chemistry and Its Application, John Wiley and Sons 